\title{
O Código Da Vinci e o encontro entre Matemática, História e
}

\section{Arte}

Resumo: O romance $O$ Código Da Vinci, escrito por Dan Brown, teve uma enorme repercussão, tendo vendido milhões de cópias em todo o mundo. Mas, foi com a sua adaptação para o cinema, em 2006, que horizontes se ampliaram, alcançando ainda mais indivíduos. Nosso objetivo é dialogar com a Matemática, a História e a Arte presentes na obra de Dan Brown, em busca da Interdisciplinaridade. Na trama, o professor Robert Langdon encontra-se com a Sequência Fibonacci, a Razão Áurea, e as obras de Arte de Leonardo Da Vinci e vários mistérios que as cercam. Um verdadeiro passeio imerso na História da Arte em diálogo com a Matemática. Para tanto, vamos nos apoiar na obra literária e no filme homônimo dirigido por Ron Howard, além de conhecimentos sobre a Razão Áurea. Acreditamos que a inserção de novas fontes pode contribuir significativamente para $o$ ensino, seja da Matemática, seja da História.

Palavras-chave: Interdisciplinaridade. Sequência Fibonacci. Razão Áurea.

\section{The Da Vinci Code and the meeting between Mathematics, History and}

\section{Art}

Abstract: The novel The Da Vinci Code, wrote by Dan Brown it had a huge repercussion, having sold millions of copies around the world. But, it was with its cinematographic adaptation in 2006 that the horizons have expanded, obtaining even more people. Our purpose is to dialogue with Mathematics, History and the Art contained in the work of Dan Brown, looking for the interdisciplinarity. In the plot, the professor Robert Langdon finds with the Fibonacci Sequence, the Golden Ratio and the works of Art of Leonardo Da Vinci; and the many mysteries that surround it. A truly walk immersed in the History of Art in dialogue with Mathematics. Therefore, we will be base in the literary work and the namesake film directed by Ron Howard, beyond knowledge. On Gonden Ratio. We believe that the insertion of new sources can help significantly to the teaching, wether of Mathematics, wether of history.

Keywords: Interdisciplinarity. Fibonacci Sequence. Golden Ratio.

\section{El Código Da Vinci y el encuentro entre Matemáticas, Historia y Arte}


Resumen: El romance El Código Da Vinci, escrito por Dan Brown, ha tenido una gran repercusión, habiendo vendido millones de copias en todo el mundo. Sin embargo, fue con su adaptación al cine, en 2006, que se ampliaron los horizontes, llegando incluso a más individuos. Nuestro objetivo es dialogar con las Matemáticas, la Historia y el Arte presentes en la obra de Dan Brown, en busca de la Interdisciplinariedad. En la trama, el profesor Robert Langdon se encuentra con la Secuencia de Fibonacci, la Razón Dorada y las obras de arte de Leonardo Da Vinci y varios misterios que las rodean. Un verdadero recorrido inmerso en la Historia del Arte en diálogo con las Matemáticas. Para ello, nos apoyaremos en la obra literaria y en la película homónima dirigida por Ron Howard, además del conocimiento sobre la proporción áurea. Creemos que la inserción de nuevas fuentes puede contribuir significativamente a la enseñanza, ya sea en Matemáticas o en Historia.

Palabras clave: Interdisciplinariedad. Secuencia Fibonacci. Proporción Áurea.

\section{Introdução}

Temos como objetivo mostrar a possibilidade de se pensar e tornar concreta a interdisciplinaridade, mesmo diante de alguns desafios e obstáculos, que a seguir mencionaremos. Quando se fala em contextualização e interdisciplinaridade, ou seja, quando se tenta relacionar a Matemática com o mundo que nos cerca ou com problemas de natureza prática, logo se encontra um problema: um programa curricular cristalizada, imóvel e inflexível, na qual alguns assuntos e áreas do conhecimento são priorizados em detrimento de outros. Naturalmente, não podemos dar conta da totalidade das coisas e temos em mente que o conhecimento é inesgotável, obrigando-nos a fazer recortes. Porém, sabemos, também, que a forma como se organiza um programa curricular, determina um posicionamento político, onde vigora um embate de interesses constantes. Diante disso, parece-nos indispensável pensarmos uma conversa entre Matemática e outras ciências, pois entendemos haver, entre elas, uma estreita ligação; pensar a interdisciplinaridade nos dias de hoje é premente.

Como pensar a Engenharia sem o estudo da Física e da Matemática? Como pensála sem a História da Arte, dos modelos arquitetônicos? Como imaginar a quebra do núcleo atômico sem lembrar os desastrosos efeitos em Hiroshima e Nagasaki? Como não lembrar as duas Grandes Guerras sem associá-las ao desenvolvimento bélico, da Química, da Computação? É possível esquecer que se matava em nome de Deus na Idade Média ou que a morte e perseguição dos judeus se deu, principalmente, por conta de um determinado indivíduo, líder de um partido, os achar uma raça biologicamente inferior? $\mathrm{E}$, é bom lembrar que o mundo temeu durante muito tempo uma guerra nuclear e a 
destruição mútua assegurada do globo.

São apenas alguns exemplos; outros poderiam ser citados, mas, por ora, esses servem para exemplificar e justificar que o diálogo entre Matemática e algumas áreas do conhecimento humano é possível e importante. Matemática, Arte e História, por exemplo, estão presentes em nossas ações do dia a dia, na Natureza e nas construções. É possível encontrá-la em momentos triviais, como um troco recebido ou passado; uma pancada na cabeça e a perda da memória e você não é mais quem era; uma pintura em muro, enfim, no mundo que nos cerca. Todavia, o mais surpreendente é o diálogo que elas podem manter, tornando ricas as nossas experiências. É o que nos proporciona a leitura da mais conhecida obra de Dan Brown, O Código Da Vinci (2004), que, mesmo sendo uma obra de ficção, deixa os leitores curiosos e instigados a buscarem uma possível presença de Matemática nesse mundo.

Não queremos dizer aqui que a interdisciplinaridade está presente em $O$ Código Da Vinci, mas sim, que esta obra servirá como um elemento motivador para ajudar a enxergar Matemática em outras áreas do conhecimento humano, ou seja, para mostrar a possibilidade de diálogo entre Matemática e Ciências. O leitor mais curioso pode se perguntar como é possível esse diálogo, e como a supracitada obra pode nos mostrar que a Matemática também está presente nessa trama. É o que pretendemos com este artigo: mostrar o trabalho de Dan Brown como incentivo aos alunos, instigando-os a conhecer um pouco mais do universo matemático presente na História e na Arte. Especificamente, com relação aos questionamentos feitos, sugerindo exemplos de como a Matemática está presente em algumas situações do nosso dia a dia, vamos tratar apenas das conexões entre Matemática, História e Arte, e de um pouco sobre como ocorre na Arquitetura.

Deste modo, exploraremos a Sequência de Fibonacci e a Razão Áurea presentes na trama, pontuando as obras de arte de Leonardo Da Vinci e vários mistérios que as cercam, bem como a presença dessa razão em outras obras de arte renascentistas, e algumas de suas propriedades, necessárias ao entendimento da Matemática envolvida nessas questões e sua conexão com as áreas citadas, tendo como pano de fundo a História da Matemática.

Veremos que a Razão Áurea tem uma grande importância interdisciplinar a partir da Sequência de Fibonacci, pois, além de estar presente nas áreas supracitadas, também 
é base de outras ciências, como a própria Matemática, Física Teórica e Computação Científica, por exemplo.

Iniciaremos esse trabalho de indicação de possibilidades de interdisciplinaridade, falando um pouco sobre o que é interdisciplinaridade, e como a Matemática da Harmonia contribui para concretizá-la. Faremos, também, um breve panorama sobre $O$ Código Da Vinci e, em seguida, como a obra de Leonardo Da Vinci nos despertou para a busca da Matemática nela presente e como Fibonacci com a sua sequência contribuiu para novos rumos, mostrando que a Matemática está em toda parte. Finalmente, como as obras de arte que mostraremos são renascentistas, uma dúvida poderá ser suscitada: e o PósRenascimento? Não o estudaremos aqui, mas faremos uma breve ligação entre o que vimos até aqui e o que será visto na Arte e na Arquitetura dos Séculos XIX e XX, falando um pouco sobre o Sistema de Proporções de Le Corbusier, que é baseado na Razão Áurea.

\section{O que é Interdisciplinaridade?}

Perguntas como "professor, pra que serve isso?", “quando e onde vou usar isso?", “por que estudar Matemática?”, “todos nós precisamos estudar Matemática?” e "de que Matemática, realmente precisamos?” que, em geral são difíceis de respondê-las, pois, além da necessidade de se conhecer bem a Matemática que será ensinada, é preciso conhecer também alguns conteúdos de outras áreas que se pretende inferir o tipo de Matemática nelas existente.

Essas perguntas provocam no professor a necessidade de dialogar com outras áreas do conhecimento humano. Posto assim, defendemos a árdua tarefa de se fazer interdisciplinar. A historiadora Nádia Santos (2020) tenciona esse debate ao nos apresentar os parâmetros estabelecidos pela LDB n 9.394 de 1996 definindo "o interdisciplinar como princípio norteador das práticas escolares” (p. 48), embora o documento "não apresente uma conceituação", afirma a autora. Durante a década de 1990 os estudos sobre interdisciplinaridade vão se tornando mais consolidados.

Nesse contexto, a autora sintetiza a compreensão dos Parâmetros Curriculares Nacionais para o Ensino Médio (PCNEM) e das Diretrizes Curriculares Nacionais do Ensino Médio (DCNEM) diante da interdisciplinaridade. O primeiro a definiu "como uma dimensão que questiona a segmentação das áreas do conhecimento, fomentada por uma 
abordagem que considera as relações de interação e influências entre elas" (SANTOS, 2020, p. 48). No segundo, vê o conceito como possibilidade de "interconexões que facilitarão a apreensão dos conteúdos de forma integrada" (SANTOS, 2020, p. 49), colocando-o como "um objeto de conhecimento, um plano de intervenção ou um projeto de investigação" (SANTOS, 2020, p. 49).

Tais observações evidenciam que a abordagem interdisciplinar possibilitaria uma visão sob várias perspectivas por parte dos alunos. Isto posto, percebemos o quanto o trabalho é delicado e árduo, pois sabemos das restrições impostas pelo próprio currículo escolar que, em geral, não abre espaço para este fim. Além disso, acentua-se a crescente necessidade de uma formação continuada dos profissionais para melhoria em suas práticas, métodos e reflexões na atividade docente (LIMA e BORBA, 2021). É árduo, ainda, nesse sentido, pois, o que se faz, no máximo, é conseguir andar apenas na fronteira entre a Matemática e algumas áreas do conhecimento humano, principalmente, porque ainda se emprega métodos tradicionais de ensino. Neste sentido,

\footnotetext{
o método tradicional de ensino se destaca em frente a outras metodologias, pois é a forma mais utilizada dentro das salas de aula, que nos remete à uma questão cultural. Na forma tradicional de ensinar, algumas características se ressaltam, como a prioridade de finalizar conteúdos em tempos determinados, independentemente de o estudante ter compreendido ou não (TIESEN e ARAÚJO, 2020, p. 1).
}

Assim, se faz necessário pensar alternativas para superação do método tradicional a partir de novas práticas de ensino com base em teorias diversificadas (CARMO, 2018). Por isso, o desafio de pôr-se o movimento de mudança dessas grades está justamente em pensar a interdisciplinaridade para além da "junção de disciplinas", como "atitude de ousadia e busca frente ao conhecimento, cabe pensar aspectos que envolvem a cultura do lugar onde se formam professores, seu aspecto Humano!" (FAZENDA, 2015, p. 9); e, ainda, compreendê-la como propósito de buscar novos questionamentos e nova postura diante do conhecimento (SANTOS, 2020; FAZENDA, 2015; JAPIASSU, 1976). Todavia, temos em mente que "toda mudança curricular é parte de uma política de desenvolvimento do país e, portanto, o currículo deve expressar coerência e articulação com esse projeto" (DOMINGUES, TOSCHI e OLIVEIRA, 2000, p. 64).

É disso que precisamos, de uma Matemática que forme cidadãos, de uma Matemática mais democrática. Isto é, acessível a todos, de modo a fazer com que ela os 
façam compreender e saber olhar para o mundo, para as coisas do nosso dia a dia. Vale a pena salientar um pouco sobre o outro lado, para alguns, contrário à interdisciplinaridade, mas que pode também ter algum valor. Hoje, apesar de uma excessiva preocupação, de um apelo enorme por aplicações da Matemática, existe também quem encontre prazer, simplesmente, no fato de se chegar à solução de um problema, tendo ele caráter prático ou não. Assim, se voltarmos aos gregos, por exemplo, no entender de Livio (2009), a excelência grega em Matemática foi, em grande parte, consequência direta de sua paixão pelo conhecimento em si mesmo e não, simplesmente, por motivos práticos.

$\mathrm{Na}$ verdade, o que desejamos é que a interdisciplinaridade possa abrir portas para os desenvolvimentos matemático e educacional em geral e de "algumas percepções nos alunos, como sensibilidade, apreciação estética e imaginação" (CHAS, 2016, p. 107), em seu diálogo com a arte, por exemplo. Com esse fim, acreditamos ser a Matemática da Harmonia, que tem estreita relação com a Razão Áurea, um elo entre a Matemática e diversas áreas do conhecimento humano; "a Matemática da Harmonia cria uma nova direção em Matemática e mostra Problemas de Harmonia, Simetria, Razão de Ouro na Natureza, Ciência e Arte, sugerindo um caminho para interdisciplinaridade" (STAKHOV, 2009, p. 11).

A Matemática da Harmonia é uma enorme contribuição teórica para o desenvolvimento da Matemática Elementar e, como tal, poderá ser considerada de grande importância para a Educação Matemática. Inclusive, Stakhov (2009) propõe a disciplina Matemática da Harmonia e Razão Áurea para cursos superiores de Pedagogia e Matemática, sugerindo uma disciplina que daria início à uma reforma da Educação Matemática, e que deveria ser baseada em princípios da Harmonia e da Razão Áurea.

Segundo Livio (2009, p. 11), o físico britânico William Thonson (1824-1907), disse que "Quando não podemos expressar algo em números, nosso conhecimento é de um tipo escasso e insatisfatório". Em outras palavras, o que Thonson quis dizer é que a Matemática está presente no mundo que nos cerca, ou seja, que a Matemática tem o poder de contribuir para coisas distantes das ciências, tornando possível, assim, o avanço dessas ciências.

Como vimos ao longo desta seção, não é tarefa fácil, tampouco simples, trabalhar a interdisciplinaridade e, por isso, propomos o uso da obra de Dan Brown e o filme 
homônimo, como elementos motivadores para a busca de nosso objetivo, com o intuito de se pensar essa interdisciplinaridade. Para darmos início ao passeio entre Matemática, História e Arte, na seção a seguir, faremos um breve panorama sobre O Código Da Vinci.

\section{O Código Da Vinci: um breve panorama}

A película exibida no ano de 2006 e dirigida por Ron Howard, assim como o livro de Dan Brown, que dá origem ao filme, tem início com a morte de Jacques Saunière, curador do Museu do Louvre, em Paris. Aliás, essa é uma marca das obras do escritor estadunidense que, em seu prólogo sempre narra o acontecimento norteador da trama, como um assassinato, um suicídio etc. Jacques, após levar um tiro desferido por Silas o corpulento homem albino que estava a serviço da Opus Dei - deixa uma série de pistas (algumas delas usando seu próprio sangue) que mais tarde serão seguidas por sua neta, Sophie Neveu, criptógrafa do Departamento de Polícia Judiciária da França, e Robert Lagdon, professor de simbologia da Universidade de Harvard, vividos na trama fílmica por Audrey Tautou e Ton Hanks, respectivamente.

Com a adaptação para o cinema, além de chegar a vários lares, a película acabou ampliando o número de leitores, uma vez que se alavancou também a venda de livros, que se tornou um best seller mundial. Mas, o que torna tão espetacular a obra de Dan Brown? Certamente, as questões levantadas pelo autor, principalmente no que toca à Igreja e alguns assuntos sensíveis, como a linhagem de sangue. Entretanto,

\footnotetext{
um dos motivos para o sucesso polêmico da obra de Dan Brown é a credibilidade que conseguiu diante dos leitores ao ambientar uma história de caráter ficcional em lugares conhecidos mundialmente, e citando nomes de artistas, pensadores e expoentes do passado ilustre da humanidade. (ROSTIROLA, 2005, p. 14).
}

Logo no início da obra literária, podemos conferir o caráter de realidade da mesma na página onde o autor denomina de FATOS, e afirma que "Todas as descrições de obras de arte, arquitetura, documentos e rituais secretos (...) correspondem rigorosamente à realidade" (BROWN, 2004, p. 9). Sem dúvida, um livro que trata de tais assuntos e ainda que seja uma trama ficcional, ao trazer essas informações acaba por instigar seus leitores, despertar dúvidas e os fazendo pesquisar, inclusive para os que se interessam por Matemática, tentar buscar a sua presença nessas obras de arte e na Arquitetura. Por isso, 
postulamos a importância do diálogo entre as demais áreas do conhecimento.

Voltemos à trama de Dan Brown. Na cena do crime, Saunière encontra-se completamente nu e deitado de barriga para cima "perfeitamente alinhado com o eixo longitudinal do aposento. Seus braços e pernas estavam bem abertos, como os de uma criança fazendo um anjo na neve... ou talvez (...), como um homem sendo puxado e esquartejado por alguma força invisível” (BROWN, 2004, p. 42). Esta é uma referência ao Homem Vitruviano, de Leonardo Da Vinci, que sabemos ter algumas proporções que instigam curiosos de várias áreas do conhecimento humano, marcando assim, um encontro entre Matemática e Arte.

No corpo humano, o ponto central naturalmente é o umbigo. Porque se o homem for deitado de costas, com as mãos e os braços estendidos e um compasso for centrado em seu umbigo, os dedos de suas mãos e de seus pés irão tocar a circunferência do círculo descrito a partir desse ponto" (VITRUVIUS, s/d apud LIVIO, 2009, p. 157).

É também na cena do assassinato do curador do museu, que Langdon encontra uma sequência numérica junto com palavras "roxas e florescentes escritas sobre os tacos do assoalho" (BROWN, 2004, p. 49). Assim aparece a mensagem de Jacques Saunière:

$$
13-3-2-21-1-1-8-5
$$

\section{O, Draconian devil!}

\section{Oh, lame saint!}

Na obra, a mensagem é traduzida por Ó demônio draconiano! Oh santa falsa! Na verdade, a mensagem de Saunière era um anagrama correspondente às frases: Leonardo Da Vinci! The Mona Lisa! E os números dispostos de modo aleatório, nada querem dizer, mas se organizados de uma dada forma pode-se obter uma sequência que faz parte da famosa Sequência de Fibonacci: 1-1-2-3-5-8-13-21. Mais uma vez, o encontro entre Matemática e Arte é assinalado na obra, que se trabalhado de forma efetiva pode contribuir, insistimos mais uma vez, como estímulo aos alunos. Além de Matemática e Arte, tem-se mais uma área que é estreitamente ligada à Matemática: a Criptografia.

Aparentemente, uma simples sequência numérica, mas que precisou do conhecimento de um criptógrafo para chegar à conclusão de que se trata de uma Sequência de Fibonacci, que veremos mais adiante, e como esta contribui para alguns avanços em Matemática, estimulando o aluno buscar a presença dessa sequência em 
Matemática e em outras áreas do conhecimento humano.

Mas, como estimular os alunos se a crescente fragmentação do saber que se assiste hoje parece, por vezes distanciar as disciplinas? Vejamos que

\begin{abstract}
o engenheiro de qualquer especialidade, entre outros conhecimentos, precisa fundamentalmente dos conhecimentos matemáticos, físicos e químicos. $\mathrm{O}$ médico dos conhecimentos biológicos. O advogado dos conhecimentos filosóficos, sociológicos, históricos, e assim por diante. Em outras palavras, o elenco das disciplinas que formam o currículo, até por imposição da legislação do ensino, é constituído por numerosas disciplinas que são aplicações dos conhecimentos de Filosofia, Matemática, Física, Química, Biologia, Geografia, História, Economia, Sociologia, Psicologia e estudo de Línguas (PAVIANI, 1993, p. 4-5).
\end{abstract}

Podemos até inferir, a partir da fala de Paviani (1993), que essas disciplinas se complementam, sendo na verdade, extensões do conhecimento de outras áreas, que não se excluem, mas sim, que se agregam. É Hilton Japiassu (1976) quem vai nos dizer da necessidade de uma intensa reflexão e inovação no conhecimento, chamando atenção para a insatisfação com o saber fragmentado. Neste ínterim, se faz mister lembrar que "a interdisciplinaridade não deve ser uma simples integração ou sobreposição de conteúdo, mas sim uma síntese" (SERENATO, 2008, p. 41), formando um novo produto, e permitindo-nos, assim, a "reinterpretações de conceitos de uma área em outra, sendo capaz, inclusive, de gerar novos métodos de trabalho e de pesquisa que atendam a todas as disciplinas envolvidas no processo" (p. 41).

Cientes dessa interlocução, dessa interface, focaremos a nossa atenção na Sequência de Fibonacci e na Razão Áurea, atentando para a relação entre Matemática e Arte; para isso, se faz necessário um passeio pela História, para melhor compreendermos como se formou essa relação ao longo dos tempos, como veremos posteriormente. Além disso, é importante mencionar como se dá a relação entre a Sequência Fibonacci e a Razão Áurea. Igualmente importante, é a figura de Leonardo Da Vinci, como poderemos evidenciar. Discorreremos sobre sua história e contribuições para Arte e Matemática, bem como o contexto no qual estava inserido. É o que faremos a seguir.

\title{
$4 O$ multifacetado Leonardo Da Vinci
}

É importante conhecermos, mesmo que minimante, a biografia de Leonardo Da 
Vinci (1452-1519), bem como o contexto no qual estava inserido. Não apenas por estarmos visitando o universo das obras de Da Vinci, na obra de Dan Brown, mas por existir uma intrínseca relação entre a Arte, a Matemática e a Razão Áurea, em especial. Ademais, continuamos mantendo a coerência em nossa proposta do diálogo interdisciplinar entre Matemática, História e Arte.

Nascido em Anchiano, Itália, Leonardo Da Vinci foi, além de pintor, escultor, arquiteto, matemático, mecânico, inventor, anatomista, químico, botânico, cartógrafo, escritor, poeta e músico, para citar apenas algumas das habilidades deste ser multifacetado. Ademais, é considerado um dos mais importantes nomes do Renascimento Italiano, também conhecido por muitos como o Homem do Renascimento.

O Renascimento foi um movimento que aconteceu em toda a Europa, mas seu nascedouro e onde ocorreu com maior nitidez, foi na Itália. Entendemos por Renascimento um momento em que se deu a valoração dos textos da Antiguidade Clássica e uma maior valorização da razão e da capacidade humana. Vale lembrar que na Idade Média já havia a preocupação em copiar e estudar os textos clássicos, mas foi com o Renascimento que se introduziu uma leitura crítica, preocupando-se com seus originais, a autoria, a fim de encontrar a pureza desses escritos (FALCON e RODRIGUES, 2006). Ademais, o termo foi cunhado bem depois de Da Vinci. Assim, define André Chastel (1999) apud Chauveau (2012):

\footnotetext{
Nas primeiras acepções desse termo (forjado um século depois de Leonardo), leva-se em conta a ressurreição das letras e das artes da Antiguidade redescoberta. Mas logo a seguir, ou simultaneamente, a mudança de perspectiva modifica o olhar que a época lança sobre o mundo. Ao colocar o indivíduo no centro do motivo, onde antes havia apenas Deus, o Ocidente começa sua conquista do mundo. É a grande promoção do Ocidente e do seu pensamento (p. 25).
}

Notemos que numa das mudanças nesse mundo moderno, que doravante encontrase despindo-se do véu da Idade Média, o homem passa a ser o senhor de seu destino e centro do mundo, tendo a sua atenção voltada, pouco a pouco, para a razão em detrimento da religião como era ou deveria ser no período anterior (SILVA, 2017). É, portanto, em meio a essas mudanças, que estaria inserido Leonardo Da Vinci.

Depois da morte do avô em 1464, Leonardo vai morar com o pai em Florença, completar seus estudos e começar o quanto antes uma profissão (CHAUVEAU, 2012). 
Segundo Chauveau (2012), há quem diga que ele foi antes do mencionado ano para o ateliê de Verrocchio, onde passaria os seis anos regulamentares de seus estudos. Os anos de estudo com Verrocchio são muito importantes e com ele Da Vinci aprenderá bastante, tornando-se um dos alunos mais notáveis de seu mestre.

Posteriormente, Leonardo parte para Milão, onde permanecerá cerca de vinte anos, que são determinantes para a sua vida. O começo, o novo, é por vezes assustador e não foi fácil seu início nessa cidade. É somente um ano depois de sua chegada a Milão, portanto, em 1483, que ele "consegue finalmente uma encomenda séria, por intermédio de Ambrogio e Evangelista Predis. Trata-se do famoso retábulo da Virgem dos Rochedos" (CHAUVEAU, 2012, p. 28).

O ano de 1496 marca a chegada de um dos maiores matemáticos da época a Milão para uma conferência — Frei Luca Pacioli —, nascendo imediatamente uma enorme admiração de Leonardo pelo trabalho de Pacioli. Este, reciprocamente, admira Da Vinci, iniciando-se uma grande amizade, e isto aumenta sua dedicação à Matemática, pois lhe faltava um mestre para "ter acesso aos cálculos de que necessita" (CHAUVEAU, 2012, p. 46).

Já o matemático Luca Pacioli, diz ter sua herança matemática advinda de Piero della Francesca, mas acaba apropriando-se deste sem a preocupação de citá-lo, conforme Chauveau. De todo modo:

Leonardo descobre aí um universo apaixonante, uma infinidade de problemas que são para ele outros tantos desafios à inteligência... Juntos, os dois logo pensam em publicar um livro, La Divina Proporzione - um dos três manuscritos se encontra hoje conservado na Biblioteca Ambrosiana em Milão -, que seria a suma de todos os conhecimentos (e empréstimos) de Pacioli. Leonardo realiza desenhos de poliedros regulares cuja perfeição fascina artistas e cientistas (CHAUVEAU, 2012, p. 46).

Finalmente, Leonardo Da Vinci é reconhecido por seus pares - matemáticos e outros cientistas —, principalmente por não ser um "homem das letras", ou seja, sem muito apreço ao latim. Em 1499, deixa Milão e segue juntamente com seu amigo Pacioli e seu assistente Salai (Gian Giacomo Caprotti da Oreno) para Veneza, passando antes por Mântua. Uma vez na nova cidade, consegue emprego de engenheiro militar e arquiteto, com a tarefa de elaborar meios de defender a cidade de um ataque naval.

Em 1503, Leonardo começa a pintar o que viria a ser uma de suas mais conhecidas 
obras: Mona Lisa ou La Gioconda. A pintura tem sua fama, principalmente por conta de seu enigmático sorriso, além, é claro, da qualidade, do uso da técnica sfumato, aplicada nos cantos dos lábios e dos olhos, dificultando perceber a natureza de seu sorriso. Outro detalhe é sua vestimenta, sem adornos, o que impede que quem a olhe não tire os olhos do rosto e das mãos, em destaque na pintura; "desse entendimento produzido pelo olhar decorria, também, a importância da matemática como instrumento de realização da absorção do que está no mundo, e Leonardo da Vinci teria injetado nesse modo de ver o mundo uma força ativa do homem" (FALCON e RODRIGUES, 2006, p. 152).

Aqui, temos mais um encontro entre Matemática e Arte. Como compreender a Matemática presente nas obras de Leonardo Da Vinci, principalmente, na Virgem dos Rochedos e na Mona Lisa (La Gioconda)? Faremos isso, ao compreender a Sequência de Fibonacci, a Razão Áurea, que vermos a partir da próxima seção.

\title{
5 Mais um Leonardo: Fibonacci e a Razão Áurea
}

\begin{abstract}
Em O Código Da Vinci, o autor Dan Brown fez com seu curador assassinado, Jacques Saunière, deixasse os oitos primeiros termos de uma sequência de números como pista sobre seu destino. Foram necessárias as habilidades da criptógrafa Sophie Neveu em reagrupar os números 13, 3, 2, 21, 1, 1, 8 e 5 para descobrir o que significavam. Bem-vindo à mais famosa sequência de números em toda a matemática (CRILLY, 2017, p. 46).
\end{abstract}

Leonardo Fibonacci, também conhecido como Leonardo de Pisa ou Leonardo Pisano, foi um dos maiores e mais talentosos matemáticos da Idade Média, nascido em 1175, na cidade de Pisa, um importante centro comercial daquela época. Filho de um homem de negócios e funcionário de governo conhecido como Guglielmo, Leonardo era movido a desenvolver e solucionar problemas matemáticos. O problema dos coelhos, um dos mais conhecidos de Fibonacci, foi proposto em seu Liber Abaci de 1202, como "Quot paria coniculorum in uno anno ex uno pario germinentur" (HEFEZ, 2006, p. 26). Em uma linguagem moderna, este problema fica conforme o Quadro 1.

Quadro 1: Problema proposto por Fibonacci - Liber Abaci (1202)

Problema: Sabendo que os coelhos se tornam produtivos depois de dois meses, começando com um casal de recém-nascidos, quantos pares de coelhos serão produzidos em um ano, supondo que a cada mês, um casal gera um novo casal?

Fonte: Elaboração dos Autores 
Nos dois primeiros meses haverá apenas 1 casal, pois ainda não reproduziram, isto é, no final do segundo mês, o casal do mês anterior (recém-nascido) se tornou adulto. A partir do terceiro mês, que começa com 2 casais ( 1 adulto e 1 recém-nascido), cada casal produzirá mais um casal, chegando-se a 3 casais no quarto mês ( 2 adultos — sendo 1 casal adulto do mês anterior, mais o recém-nascido do mês anterior que se tornou adulto neste mês - mais 1 reproduzido pelo casal adulto do mês anterior). Continuando assim, no quinto mês, teremos 5 casais, sendo 3 adultos e 2 recém-nascidos, de acordo com a análise anterior, 8 casais no sexto mês, e assim por diante, até chegarmos a 144 casais no $12^{\circ}$ mês. Na Tabela 1, encontra-se a solução de Fibonacci, que mostra a população de coelhos em cada mês.

Tabela 1: Solução de Fibonacci para o problema dos coelhos

\begin{tabular}{c|c|c|c}
\hline Mês & $\begin{array}{c}\text { Número de casais } \\
\text { do mês anterior }\end{array}$ & $\begin{array}{c}\text { Número de casais } \\
\text { recém-nascidos }\end{array}$ & Total \\
\hline $1^{\circ}$ & 0 & 1 & 1 \\
\hline $2^{\circ}$ & 1 & 0 & 1 \\
\hline $3^{\circ}$ & 1 & 1 & 2 \\
\hline $4^{\circ}$ & 2 & 1 & 3 \\
\hline $5^{\circ}$ & 3 & 2 & 5 \\
\hline $6^{\circ}$ & 5 & 3 & 8 \\
\hline $7^{\circ}$ & 8 & 5 & 13 \\
\hline $8^{\circ}$ & 13 & 8 & 21 \\
\hline $9^{\circ}$ & 21 & 13 & 34 \\
\hline $10^{\circ}$ & 34 & 21 & 55 \\
\hline $11^{\circ}$ & 55 & 34 & 89 \\
\hline $12^{\circ}$ & 89 & 55 & 144 \\
\hline
\end{tabular}

Fonte: Elaboração dos Autores

Portanto, o número de casais em um determinado mês é igual ao número total de casais do mês anterior, acrescido do número de casais recém-nascidos (casais do mês em curso), que é o número de casais adultos do mês anterior, gerando-se assim, a sequência de números inteiros da forma $1,1,2,3,5,8,13,21,34, \ldots$, conhecida como Sequência de Fibonacci. Assim, a Sequência será determinada como segue: os dois primeiros elementos da sequência são iguais a 1, e um elemento qualquer, a partir do terceiro, é igual à soma 
dos dois anteriores.

De maneira geral, define-se a Sequência de Fibonacci assim: se $f_{\mathrm{n}}$ é um termo qualquer da sequência, então $f_{\mathrm{n}}=f_{\mathrm{n}-1}+f_{\mathrm{n}-2}, f 1=f 2=1$ e os seus termos $1,1,2,3,5,8$, 13, 21, 34, ..., são chamados de números de Fibonacci.

A Sequência de Fibonacci não ficou esquecida no passado; pelo contrário, ao longo dos tempos matemáticos e pesquisadores de outras áreas mostraram que ela possui várias propriedades importantes para além da Matemática, e que fazem com que tal sequência esteja na base de outras ciências, fazendo também, com que seja possível o computador de Fibonacci (STAKHOV, 2009), mostrando também uma relação desta sequência com a computação, além de outras áreas já mencionadas. Para um aprofundamento em tais propriedades, ver Vorobiov (1974). Vamos agora mostrar como a Sequência de Fibonacci está relacionada com a Razão Áurea, a relação destes com o Retângulo Áureo, e como essa razão aparece na trama de Dan Brown.

\subsection{Razão Áurea (Número de Ouro)}

Algumas denominações para a Razão Áurea, como número áureo, número dourado, divina proporção ou proporção áurea, são encontradas na literatura. É um número irracional positivo, representado por $\mathrm{Fi}(\phi)$, no início do século $\mathrm{XX}$, pelo engenheiro americano Mark Barr, em homenagem ao escultor e arquiteto grego Fideas (490 - 430 a.C.). Entre as realizações de Fideas, estão o Parthenon de Atenas — segundo alguns autores, há indícios da presença da razão áurea na sua fachada —, um templo dedicado à deusa grega Atena, construído no século V a.C., na Acrópole de Atenas, no templo de Olímpio, na Grécia Antiga.

Essa razão ficou conhecida entre os gregos, com Euclides ( \pm 300 a.C.), que a definiu, na tentativa de construção do pentagrama, com o nome de média e extrema razão. Era tão importante entre os antigos gregos, que era chamada, simplesmente, a média ou a razão. O nome Razão Áurea surgiu tempos depois, quando o astrônomo e matemático Johannes Keppler (1571 - 1630), na tentativa de criar um modelo matemático para o Sistema Solar, teve contato com a obra de Euclides. Keppler ficou tão admirado com o que viu, que pronunciou as seguintes palavras sobre número de ouro: "A Geometria tem dois tesouros: um é o Teorema de Pitágoras; o outro, a divisão de um segmento em média 
e extrema razão. O primeiro, podemos comparar à medida de ouro; o segundo, podemos chamar de joia preciosa" (ÁVILA, 1985, p. 14) De todos os nomes supracitados, usaremos apenas Razão Áurea, cujo significado matemático daremos a seguir.

Um detalhe interessante a ser observado no filme $O$ Código Da Vinci é a proximidade entre a Sequência de Fibonacci e a Razão Áurea, sendo que, por algumas vezes, as expressões número dourado e Sequência de Fibonacci são mencionadas no filme. Como, logo no início, vários homens discutindo sobre o número dourado, os números que foram encontrados no chão do Museu do Louvre, deixado pelo curador do museu, Jacques Saunière, são a senha que abre o cofre no Banco de Custódia de Zurique, onde está guardado um críptex projetado por Leonardo Da Vinci. São muitas as contribuições de Leonardo Fibonacci para o que hoje conhecemos como Razão Áurea, um número que, como a sequência que leva seu nome, pode ser encontrada em várias áreas do conhecimento humano.

O problema de determinar a Razão Áurea de um segmento, foi formulado e proposto por Euclides como o problema de divisão de um segmento em média e extrema razão no Livro II de Os Elementos. Ao longo dos tempos, devido às traduções do grego para outras línguas, alguns autores vão dando as suas versões sobre esse problema, e uma delas, em uma linguagem moderna, temos que a

\footnotetext{
“divisão de um segmento em média e extrema razão", como a divisão de um segmento em duas partes desiguais com uma propriedade bem particular: o quociente entre o segmento inteiro e a parte maior é igual ao quociente do segmento maior pelo segmento menor (BELINI, 2015, p. 16).
}

Na versão portuguesa (Brasil) de Os Elementos de Euclides, tradução e introdução de Irineu Bicudo, o "problema de divisão de um segmento em média e extrema razão" (EUCLIDES, 2009, p. 146), foi formulado como mostrado no Quadro 2.

Quadro 2: Teorema II. 11

Teorema II.11. Cortar a reta dada, de modo a o retângulo contido pela parte inteira e por um dos segmentos ser igual ao quadrado sobre o segmento restante.

Fonte: Euclides (2009, p. 146)

Vamos usar a versão de Euclides para interpretar geometricamente o "problema de divisão de um segmento em média e extrema razão", que será mostrado na seção seguinte. 


\subsection{Teorema II.11}

Quadro 3: Problema de divisão de um segmento em média e extrema razão

Dividir um segmento $\overline{\mathrm{AB}}$ em dois segmentos, um maior $\overline{\mathrm{AC}}$, e um menor $\overline{\mathrm{BC}}$, tal que a área do quadrado de lado $\mathrm{AC}$ é igual à área do retângulo de lados $\mathrm{AB}$ e $\mathrm{CB}$, isto é, $\mathrm{AC}^{2}=\mathrm{AB} \times \mathrm{CB}(\mathbf{1})$.

Fonte: Euclides (2009, p. 146)

Solução: Para resolver este problema, inicialmente, considere um segmento $\overline{\mathrm{AB}}$. Construa um quadrado ABDE, de lado igual a $\overline{\mathrm{AB}}$. Sendo $\mathrm{F}$ o ponto médio de $\overline{\mathrm{EA}}$, construa, com centro em $\mathrm{F}$ e raio $\overline{\mathrm{FB}}$ um círculo que interceptará a semirreta $\overrightarrow{\mathrm{FA}}$ no ponto G. Com centro em $\mathrm{G}$ e raio $\overline{\mathrm{AG}}$, construa um círculo que interceptará a semirreta de origem $\mathrm{G}$ e paralela ao segmento $\overline{\mathrm{AB}}$, no ponto $\mathrm{H}$ e, por $\mathrm{H}$ construa o segmento $\overline{\mathrm{HI}} \perp \overline{\mathrm{AB}}$, que intercepta $\overline{\mathrm{AB}}$ e $\overline{\mathrm{ED}}$ nos pontos $\mathrm{C}$ e I, respectivamente. Agora, com centro em $\mathrm{C}$ e raio $\overline{\mathrm{CB}}$, construa o arco $\mathrm{BJ}$, com $\mathrm{J} \in \overline{\mathrm{CH}}$ e, por $\mathrm{J}$ conduza a reta $r \| \overline{\mathrm{AB}}$ e tal que $r \cap \overline{\mathrm{AG}}=\{\mathrm{K}\}$. Por fim, construa a semirreta $\overrightarrow{\mathrm{BL}} \perp r, \operatorname{com}\{\mathrm{L}\}=\overrightarrow{\mathrm{BL}} \cap r$.

Resultado: $\mathrm{AC}^{2}=\mathrm{AB} \times \mathrm{CB}$.

Justificativa: A área do trapézio ECHG é igual à área do trapézio ECBD. Segue-se daí, que a área do quadrado ACHG é igual à área do retângulo ABLK, isto é $\mathrm{AC}^{2}=$ $\mathrm{AB} \times \mathrm{CB}$.

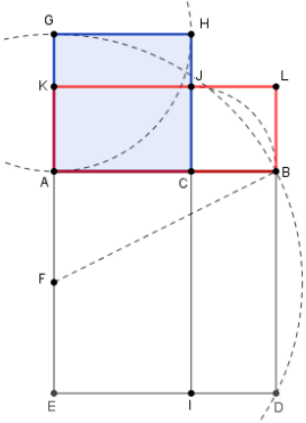

Figura 1: Interpretação Geométrica do Teorema II. 11 de Euclides (Arquivo dos Autores)

Observe que a Equação (1) pode ser reescrita como

$$
\frac{\mathrm{AB}}{\mathrm{AC}}=\frac{\mathrm{AC}}{\mathrm{CB}}
$$

Geometricamente, a Equação (2) pode ser interpretada da seguinte maneira: O ponto $\mathrm{C}$ divide o segmento $\overline{\mathrm{AB}}$ em dois outros segmentos, um maior, $\mathrm{AC}$, e um menor $\mathrm{CB}$, de modo que a razão entre a parte maior e o segmento é igual à razão entre a parte menor 
e a parte maior. Esta razão, chamada de Razão Áurea, será definida como segue.

Seja $\mathrm{C}$ um ponto que divide um segmento $\overline{\mathrm{AB}}$ em duas partes: $\mathrm{AC}=a$ e $\mathrm{CB}=b$, com $a>b$. Dizemos que $\mathrm{C}$ divide $\overline{\mathrm{AB}}$ na Razão Áurea, quando

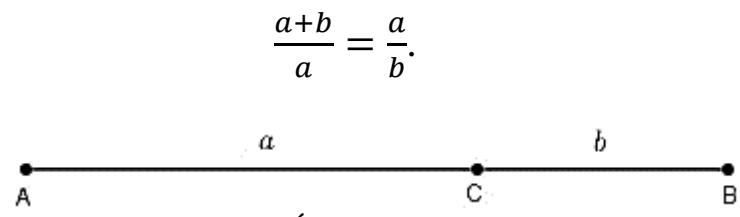

Figura 2: Razão Áurea (Arquivo dos Autores)

Em (3), fazendo $\frac{a}{b}=\phi$, temos

$$
\phi=\frac{a}{b}=\frac{a+b}{a}=1+\frac{b}{a}=1+\frac{1}{\frac{a}{b}}=1+\frac{1}{\phi},
$$

ou seja, $\phi=1+\frac{1}{\phi}$. Daí, $\phi^{2}-\phi-1=0$, cuja raiz positiva é o número $\phi=\frac{1+\sqrt{5}}{2}$, chamado de Razão Áurea. Calculando o valor de $\phi$, com uma aproximação de três casas decimais, temos $\phi \cong 1,618$.

Sobre a relação entre a Sequência de Fibonacci e a Razão Áurea, existe alguma? Sim. Vejamos o que alguns autores dizem sobre essa relação do ponto de vista de matemáticos, neste caso, Johannes Kepler que, segundo Belini (2015, p. 38), "notou em 1611, que a divisão entre um número de Fibonacci e seu precedente leva ao número $\phi$ quando se avança para valores cada vez maiores na sequência", o que pode ser comprovado analisando a Tabela 2, ao dividirmos um termo qualquer da Sequência de Fibonacci pelo seu anterior, considerando uma aproximação de 3 casas decimais.

Tabela 2: Divisão de um número de Fibonacci pelo seu anterior

\begin{tabular}{|c|c|c|c|c|c|c|c|c|c|c|c|c|c|c|c|c|}
\hline 1 & 2 & 3 & 5 & 8 & 13 & 21 & 34 & 55 & 89 & 144 & 233 & 377 & 610 & 987 & 1597 & 2584 \\
\hline$\overline{\mathbf{1}}$ & $\overline{\mathbf{1}}$ & $\overline{2}$ & $\overline{3}$ & $\overline{5}$ & 8 & $\overline{13}$ & $\overline{21}$ & $\overline{34}$ & $\overline{55}$ & 89 & $\overline{144}$ & $\overline{233}$ & $\overline{377}$ & $\overline{610}$ & $\overline{987}$ & $\overline{1597}$ \\
\hline 1,000 & 2,000 & 1,500 & 1,666 & 1,600 & 1,625 & 1,615 & 1,619 & 1,617 & 1,618 & 1,617 & 1,618 & 1,618 & 1,618 & 1,618 & 1,618 & 1,618 \\
\hline
\end{tabular}

Fonte: Elaboração dos Autores

Observemos que, à medida que o número de termos da sequência cresce, o quociente entre um termo qualquer dessa sequência e o anterior se aproxima de $\phi=$ $\frac{1+\sqrt{5}}{2} \cong 1,618$, alternando um maior e um menor, e a partir do $12^{\circ}$ termo, o algarismo da terceira ordem decimal é sempre 8. Ávila (1985) foi mais além, mostrando que a Sequência de Fibonacci e a Razão Áurea se relacionam da seguinte maneira:

$$
\lim _{n \rightarrow \infty} \frac{f_{n}}{f_{n-1}}=\phi=\frac{1+\sqrt{5}}{2} .
$$


Na relação que acabamos de verificar, vimos que $\phi$ pode ser obtido a partir do quociente $\frac{f_{n}}{f_{n-1}}$, onde $f_{n}$ e $f_{n-1}$ são termos da Sequência de Fibonacci. Agora, de maneira inversa, podemos, por meio de potências de $\phi$ determinar qualquer termo $f_{n}$ da Sequência de Fibonacci, segundo a expressão

$$
f_{n}=\frac{1}{\sqrt{5}}\left(\phi^{n}-(1-\phi)^{n}\right)=\frac{1}{\sqrt{5}}\left(\phi^{n}-\phi^{-n}\right) .
$$

A partir de, aparentemente, um simples experimento com coelhos, Fibonacci contribui de modo inconsciente para que a Razão Áurea fosse expandida, fazendo com que o Renascimento fornecesse, também, importantes contribuições para Matemática, História, Arquitetura e Arte. É o que veremos a seguir.

\section{A medida de todas as coisas: a Divina Proporção}

O Renascimento produziu uma importante mudança de direção na história da Razão Áurea. A partir de então, esse conceito deixou de ficar restrito à Matemática. Agora, a razão Áurea encontrava um caminho nas explicações dos fenômenos naturais e nas artes (LIVIO, 2009, p. 183).

Havia na cultura renascentista uma crença de que o Universo era um plano matemático de Deus e como a Razão Áurea, supostamente, estava presente em tudo, fazendo ligações de Deus com suas propriedades, ganhou o status de Divina Proporção, expressão devida a Luca Pacioli, segundo Livio (2009). Luca nasceu em 1445 no Borogo San Sepolcro e teve sua educação infantil na oficina de Piero della Francesa, pintor italiano do período do Renascimento. Muitos dos pintores naquela época utilizavam Matemática em suas obras, inclusive, Leonardo Da Vinci via como fundamental o pintor ter conhecimentos de Matemática, pois teriam facilidade nos estudos de perspectivas dos ambientes e proporções do corpo humano. Piero se destacava entre os demais porque tinha trabalhos ligados à Matemática; destes foram preservados De Prospectiva Pingendi, Libellus de Quinque Corporibus Regularibus e Trattato d'Abaco.

Quando o assunto era Divina Proporção, Luca delirava. Em uma de suas obras Divina Proportione, ele apresenta cinco motivos pelos quais a Razão Áurea deveria se chamar de Divina Proporção: 
Trindade e a definição da razão áurea envolver exatamente três comprimentos. A terceira razão consistiria na impossibilidade da compreensão de Deus e o fato de a razão áurea ser um número irracional (...). Como quarta razão, Pacioli compara a onipresença e a invariabilidade de Deus com a auto-similaridade associada à razão áurea (...). A quinta razão indica uma visão ainda mais platônica da existência do que expressa pelo próprio Platão. (SOUZA, 2013, p. 23-24).

Dos objetos matemáticos, destaca-se um que pode trazer harmonia, beleza e estética à Arte e à Arquitetura, por meio da Divina Proporção - o Retângulo Áureo, conhecido por alguns como a própria Divina Proporção. Este é considerado por artistas e arquitetos um retângulo bem proporcionado, sendo que

os retângulos estão por toda parte — prédios, fotografias, janelas, portas, até este livro. Os retângulos estão presentes dentro da comunidade dos artistas Piet Mondrian, Bem Nicholson e outros, que progrediram na direção da abstração, todos usaram um tipo ou outro de retângulo. Então qual é o mais bonito de todos? Será um "retângulo de Giacometti?", longo, fino, ou um retângulo que seja quase um quadrado? Ou será um retângulo entre esses dois extremos? (CRILLY, 2017, p. 50).

O Retângulo Áureo - Um retângulo ABCD é dito Retângulo Áureo (Retângulo de Ouro) quando dele suprimimos um quadrado, como ADEF, restando um retângulo, FECB, semelhante ao retângulo original (Figura 3). Isto significa que se $a+b$ e $a, a>$ $b$, são as medidas dos lados do retângulo original, então

$$
\frac{a+b}{a}=\frac{a}{b}
$$

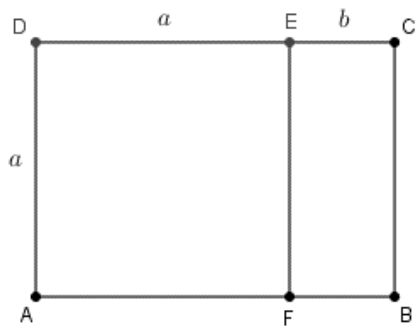

Figura 3: Rerângulo Áureo (Arquivo dos Autores)

Como as equações (3) e (4) são equivalentes, temos que em um Retângulo Áureo o quociente entre os seus lados é igual à Razão àurea, ou seja, um retângulo é áureo quando o quociente entre a sua altura e a sua base é igual a $\phi$ (Figura 3).

Acredita-se que a Razão Áurea já era usada há muito tempo, pois existem alguns relatos que atestam a sua presença nas Grandes Pirâmides do Egito, pelo menos 2500 anos a.C, e, mais recente, por volta de 2000 a. C, em alguns tabletes cuneiformes 
encontrados na Mesopotâmia. Essa suposição deve-se a algumas investigações de aficionados por esta razão que imaginavam a sua presença em algo e achavam que poderiam encontrá-la onde a imaginação permitia, causando um verdadeiro numerismo áureo que, em algumas situações a presença dessa razão era algo mais forçado do que propriamente real. Para comprovar isso, também, há relatos que garantem realmente a sua presença em alguns monumentos e obras de arte, principalmente, depois de Euclides, e outros que não passam de meras suposições, que nada comprovam, e que podem ser encontrados em Livio (2009).

Podemos observar que, possivelmente, ela está presente na construção do Parthenon (Século V, a. C.), na sua fachada, pois a razão entre a altura e a largura é muito próximo de $\phi$. Dizemos, possivelmente, mesmo depois de se notar a preocupação dos arquitetos da antiguidade em construir obras com proporções harmônicas, porque não há evidências de que ele tenha sido construído usando-se a Razão Áurea, já que foi construído antes da criação dessa razão por Euclides ( \pm 300 a.C.). Na Figura 4, podemos ver alguns retângulos na fachada do Parthenon; medindo-se o maior e menor dos lados desses retângulos e dividindo-os, obtém-se algo bem próximo de 1,618, valor aproximado de $\phi$.

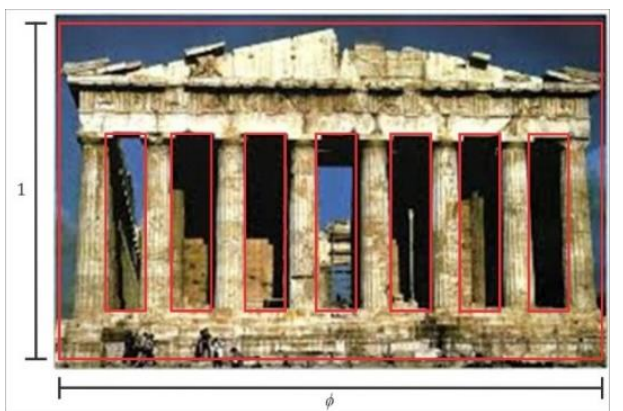

Figura 4: O Parthenon (Adaptada pelos Autores)

Ao falar de Leonardo Da Vinci, comentamos sobre suas obras e relações com a Matemática, e citamos duas delas: A Virgem dos Rochedos e A Mona Lisa. É em A Mona Lisa que faremos nossas discussões, buscando detectar nela a presença da Razão Áurea por meio do Retângulo Áureo. Sabemos que seu autor, Leonardo Da Vinci, era um aficionado por Matemática e defendia que um pintor deveria estudar Matemática e aplicála em suas obras. Na Figura 5, fazemos uma análise dessa obra, mostrando a presença de alguns retângulos áureos, dando a mesma um padrão de beleza, simetria e harmonia. 

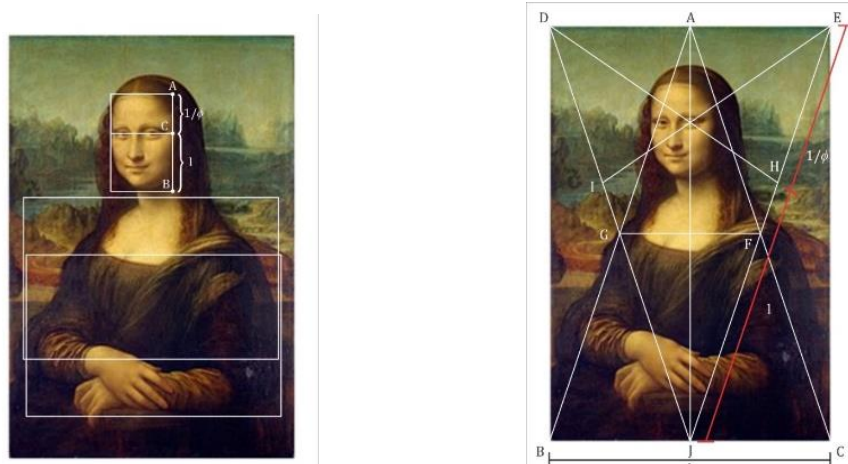

Figuras 5 e 6: Análise harmônica - “A Mona Lisa”: retângulo áureo (Adaptada pelos Autores)

Vamos apresentar outras obras de arte em que aparecem a Razão Áurea, por meio do pentagrama, do Triângulo Áureo, e do dodecaedro regular, um sólido de Platão. Na Figura 7a, temos um pentágono regular cujos lados medem 1 unidade, e sua diagonal $\mathrm{BD}=1+\frac{1}{\phi}$, ou seja, $\mathrm{BD}=\phi$. Duas das diagonais de um pentágono regular interceptamse em um ponto que as dividem na Razão Áurea: $\frac{\mathrm{BD}}{\mathrm{BF}}=\phi$. Isto mostra a capacidade de se construir um segmento dividido em sua Razão Áurea, e nos dá ao mesmo tempo uma maneira de se construir um pentágono regular.

Ainda na Figura 7a, observe que o $\triangle \mathrm{DAB}$ é um triângulo isósceles, com ângulos medindo $72^{\circ}, 36^{\circ}$ e $36^{\circ}$. Um triângulo com essa característica, é chamado Triângulo Áureo (triângulo de ouro), que também é caracterizado pelo seguinte fato: a razão entre um de seus lados e a base é igual a $\phi$. O Triângulo Áureo aparece na Figura 6, ao fazermos mais uma vez uma análise no quadro a Mona Lisa. Novamente a Geometria, agora por meio de um triângulo, dando um padrão de beleza, harmonia e simetria a essa obra.

(a)

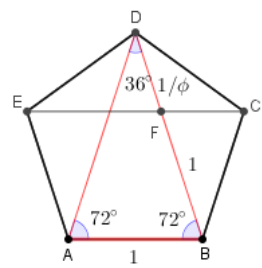

(b)

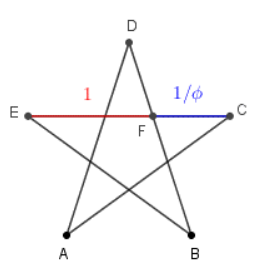

Figura 7: O Pentágono Regular (a) e o Pentagrama (b) (Arquivo dos Autores)

É interessante notar em um Triângulo Áureo $(\triangle \mathrm{ABD}-$ Figura $7 \mathrm{a})$ que $\cos 36^{\circ}=$ $\frac{\phi}{2}$, e como $36^{\circ}+54^{\circ}=90^{\circ}$, temos que $\operatorname{sen} 54^{\circ}=\frac{\phi}{2}$, e como $666^{\circ}=2 \times 360^{\circ}-54^{\circ}$, temos que $\operatorname{sen} 666^{\circ}=-\frac{\phi}{2}$, mostrando que até um número considerando apocalíptico tem relação com a Razão Áurea, além do sagrado, como já vimos. 
Na Figura 9, novamente o Triângulo Áureo, agora na obra de Rafael Sanzio, outro pintor renascentista italiano, intitulada A Crucificação de Cristo com a Virgem Maria, Santos e Anjos. Nesse quadro, há um triângulo $\triangle \mathrm{ABC}$ isósceles, cuja base mede 1 unidade e os outros dois lados medem $\phi$, cada um. Observemos que há uma simetria: Cristo Crucificado é o eixo de simetria, ladeado por anjos dispostos simetricamente em relação ao Cristo, como se estivesse observando os santos a partir do vértice A, também dispostos de forma simétrica, um em cada um dos vértices $B$ e C da base desse triângulo, que é áureo. Na Figura 7b, temos um pentagrama, considerado símbolo da Escola Pitagórica, e inspiração de Euclides para a criação da Razão Áurea. Nesse pentagrama, tem-se EC = $\mathrm{EF}+\mathrm{FC}=1+\frac{1}{\phi}=\phi$.

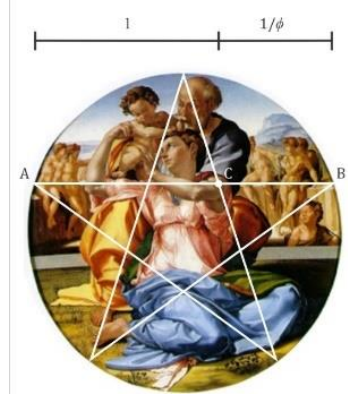

Figura 8: A Sagrada Família - Michelangelo, 1504 (adaptada pelos Autores)

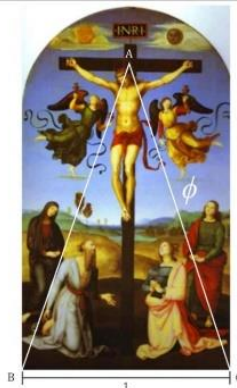

Figura 9: Crucificação de Cristo com a Virgem Maria, Santos e Anjos — Rafael Sanzio, 15021503 (adaptada pelos Autores)

A simetria, harmonizada pelas proporções do pentagrama também nos permite detectar a presença da Razão Áurea em A Família Sagrada (Figura 8), de Michelangelo. Nela, a figura de Maria está no centro do pentagrama, também fazendo a simetria dessa obra, e o ombro de José medindo $2-\phi$, com o ponto $C$, de secção do segmento $\overline{\mathrm{AB}}$, no antebraço de José. Uma inspeção com mais detalhes da Figura 8, mostra que outras relações envolvendo essa obra e o número $\phi$ podem ser encontradas.

A Razão Áurea está presente nas dimensões e propriedades de simetria de alguns sólidos platônicos que podem ser inscritos em uma esfera. Destes sólidos, vamos fazer referência ao dodecaedro regular, cuja área total de sua superfície é igual a $\frac{15 \phi}{\sqrt{3-\phi}}$ e cujo volume é igual a $\frac{5 \phi^{3}}{6-2 \phi}$. Na Figura 10, vimos a obra O Sacramento da Última Ceia, de Salvador Dalí, e nela um enorme dodecaedro regular, inscrito numa esfera que cobre a mesa, que é um retângulo sobre o círculo do equador dessa esfera. Será esse um Retângulo Áureo? Não sabemos se Dalí tinha a intenção de usar nessa obra a Razão Áurea, mas nela 
há a introdução do dodecaedro regular que, como vimos, tem relação com essa razão, e que ele era estudioso do Renascimento, principalmente, das obras de Da Vinci. As medidas desse quadro são $166,7 \mathrm{~cm}$ por $267 \mathrm{~cm}$, e $\frac{267}{166,7} \cong 1,6$, que é próximo de $\phi$.

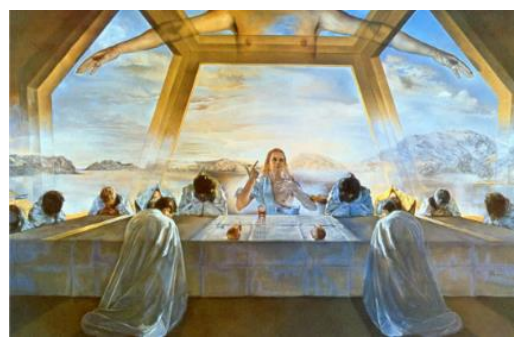

Figura 10: O Sacramento da Última Ceia — Salvador Dali, 1955 (Imagem da Internet)

Como vimos até aqui, por meio da Razão Áurea, a Matemática está presente em quase tudo que podemos ver, tocar e sentir, uma ciência que está o todo tempo sendo descoberta, e aperfeiçoada. Fixados na Razão Áurea, alguns vocacionados por numerologia e simbologia, afirmam enxergá-la em uma variedade de suposições, como em $O$ Código Da Vinci. No filme $O$ Código Da Vinci, o Homem Vitruviano aparece na cena do crime, a morte de Jacques Saunière, representando a divina proporção.

Dan Brown volta a encontrar o número $\phi$ na figura do Homem de Vitrúvio, o desenho de Leonardo. Mas aí inventa uma relação inexistente. Na realidade, esse desenho baseia-se em proporções simples para a figura humana, proporções expressas em números inteiros e não em números irracionais (CRATO, 2009, p. 108).

Na verdade, em O Homem Vitruviano, enxergam-se outras proporções que não necessariamente estão relacionadas com a Divina Proporção, mas que servem de modelo e inspiração para a criação da Arquitetura Moderna. O famoso arquiteto francês do século XX, Le Corbusier, cria o Modulor, sistema de proporções baseado na Razão Áurea, utilizada atualmente na Arquitetura. Le Corbusier era fascinado pelo retângulo como um elemento central no projeto de arquitetura e pelo Retângulo Áureo, em particular.

Segundo Crilly (2017), Le Corbusier colocava grande ênfase na harmonia e na ordem. Encontrava isso na Matemática, e via a Arquitetura por meio dos olhos de um matemático. Inspirado por Leonardo da Vinci que, por sua vez tinha anotado cuidadosamente os trabalhos do arquiteto romano Vitrúvio e, valorizando as proporções encontradas na figura humana, Le Corbusier criou um sistema de proporção, chamado de sistema Modulor, uma teoria de proporções baseada no número $\phi$. Dessa maneira, 
Le Corbusier sugeriu que o Modulor daria proporções harmoniosas a tudo, de tamanhos de gabinetes e maçanetas a edifícios e espaços urbanos. Em um mundo com uma crescente necessidade de produção em massa, esperava-se o Modulor fornecesse um modelo de padronização (LIVIO, 2009, p. 198).

Vimos que artistas e arquitetos, tantos os da Antiguidade, quanto os renascentistas, foram fascinados pela Razão Áurea e pelas medidas do corpo humano. Essa fascinação continua nos séculos XIX e XX, chegando ao ponto de se criar um sistema de proporções para a Arquitetura baseado na Razão Áurea e na Sequência de Fibonacci, o Modulor, de Le Corbusier, o primeiro sistema moderno de proporções para a Arquitetura.

Falamos da Razão Áurea e de sua relação com algumas áreas do conhecimento humano, inclusive como sendo a base de um sistema de proporções utilizado pela Arquitetura Moderna. Mas, e antes do Renascimento e dos séculos XIX e XX? Havia algum sistema de proporções utilizados por povos mais antigos? A título de curiosidade, entre os romanos dos séculos I e II, havia um sistema de proporções baseado nos números $\sqrt{2}$ e $1+\sqrt{2}$ (razão de prata).

\section{Considerações Finais}

Temos em mente, com este trabalho, poder observar no romance $O$ Código $\mathrm{Da}$ Vinci ou na película homônima, que nos serviram de mote para discutirmos em sala de aula vários assuntos, entre eles, a Sequência de Fibonacci e a Razão Áurea, e a relação destas com o mundo que nos cerca, como ao que nos propomos aqui. Ressaltamos, ainda, o importante papel da interdisciplinaridade, o diálogo com outras áreas do conhecimento humano para melhorar o ensino aprendizagem dos discentes.

Reforçamos que a interdisciplinaridade não significa colocar um profissional de Física para ministrar aula de Matemática ou um de Química para dar uma aula de Biologia, o que também se aplica a História, Geografia, Artes e áreas afins. Deve ser estimulado o diálogo entre esses profissionais. Todavia, sabemos da complexidade de se efetivar essa ação por conta da carga horária dos professores, a quantidade de trabalho que os cerca, e o fato de terem também que estudar conteúdos de outras disciplinas, e uma possível saída para solucionador esse problema, fosse uma mudança curricular.

Acreditamos que se uma mudança curricular for possível, com o fim de tornar a interdisciplinaridade uma ação concreta, sugerimos um trabalho com a Matemática da 
Harmonia que toca as bases de muitas áreas do conhecimento humano, como Física Teórica e Computação Científica, além de Matemática, importante, principalmente, para os nossos alunos de Licenciatura em Matemática, futuros professores.

Vimos que, a leitura de $O$ Código Da Vinci, e da inspeção sobre o que as suas curiosidades instigam, nos levou a pensar como a Matemática atravessa fronteiras, adentrando ao terreno de outras ciências, e poderia ser usada para compreender além da Matemática, sugerindo e contribuindo com possibilidades para a interdisciplinaridade.

\section{Referências}

ÁVILA, Geraldo. Retângulo áureo, divisão áurea e sequência de Fibonacci. Revista do Professor de Matemática, Rio de Janeiro, n. 6, p. 9-14, jan./jun. 1985.

BELINI, Marcelo Manechine. A Razão Áurea e a Sequência de Fibonacci. 2015. 67f. Dissertação (Mestrado Profissional em Matemática em Rede Nacional) - Instituto de Ciências Matemáticas e de Computação. Universidade Estadual de São Paulo. São Carlos.

BROWN, Dan. O Código da Vinci. Tradução de Celina Cavalcante Falck-Cook. Rio de Janeiro: Sextante, 2004.

CARMO, Fernanda Maria Almeida do. As tendências em Educação Matemática e sua inclusão na formação e na prática docente. 2018. 55f. Trabalho de Conclusão de Curso (Graduação em Matemática) - Faculdade de Educação, Ciências e Letras do Sertão Central. Universidade Estadual do Ceará. Quixadá.

CHAS, Dijalmary Matos Prates. Matemática e interdisciplinaridade: um estudo sobre os materiais didáticos. Estação Científica, Macapá, v. 6, n. 3, p. 97-109, set./dez. 2016.

CHAUVEAU, Sophie. Leonardo da Vinci. Tradução de Paulo Neves. Porto Alegre, 2012.

CRATO, Nuno. A Matemática das coisas: do papel A4 aos cordões de sapatos, do GPS às rodas dentadas. São Paulo: Editora Livraria da Física, 2009.

CRILLY, Tony. 50 Ideias de Matemática que Você Precisa Conhecer. Tradução de Helena Londres. São Paulo: Planeta, 2017.

DOMINGUES, José Juiz; TOSCHI, Nirza Seabra; OLIVEIRA, José Ferreira de. A reforma do Ensino Médio: a nova formulação curricular e a realidade da escola pública. Educação \& Sociedade, Campinas, n. 70, p. 63-79, abr. 2000.

EUCLIDES. Os Elementos. Tradução e Introdução de Irineu Bicudo. São Paulo: EdUNESP, 2009.

FALCON, Francisco; RODRIGUES, Antonio Edmilson. A formação do mundo moderno. Rio de Janeiro: Elsevier, 2006. 
FAZENDA, Ivani Catarina Arantes. Interdisciplinaridade: Didática e Prática de Ensino. Interdisciplinaridade, São Paulo, v. 1, n. 6, p. 9-17, abr. 2015.

HEFEZ, Abramo. Elementos de Aritmética. Rio de Janeiro: SBM, 2006.

JAPIASSU, Hilton. Interdisciplinaridade e patologia do saber. Rio de Janeiro: Imago Editora, 1976.

LIMA, Ana Paula Barbosa de; BORBA, Rute Elizabete de Souza Rosa. Comunidades de Prática e a formação do professor que ensina Matemática revisitando teses e dissertações. Educação Matemática Debate, Montes Claros, v. 5, n. 11, p. 1-30, 2021.

LIVIO, Mario. Razão Áurea: a história de Fi, um número surpreendente. Tradução de Marco Shinobu Matsumura. Rio de Janeiro: Record, 2009.

PAVIANI, Jayme. Interdisciplinaridade ou uma nova disciplina. Caxias do Sul: EdUCS, 1993.

ROSTIROLA, Sabrina. O Código da Vinci: uma leitura da perspectiva pós-moderna. ACTA Científica, São Paulo, v. 3, n. 2, p. 7-16, jul./dez. 2005.

SANTOS, Nádia Narcisa de Brito. A cor (in)visível: representações acerca da negra e do negro a partir de abordagens interdisciplinares em livros didáticos (PNLD, Guia 2018). 2020. 213f. Dissertação (Mestrado Interdisciplinar em História e Letras) — Faculdade de Educação, Ciências e Letras do Sertão Central. Universidade Estadual do Ceará. Quixadá.

SERENATO, Liliana Junkes. Aproximações interdisciplinares entre Matemática e Arte: resgatando o lado humano da Matemática. 2008. 163f. Dissertação (Mestrado em Educação) - Setor de Educação. Universidade Federal do Paraná. Curitiba.

SILVA, Odair Vieira da. A Idade Moderna e a ruptura cultural com a tradição medieval: reflexões sobre o Renascimento e a Reforma Religiosa. Revista Científica Eletrônica da Pedagogia, Garça, v. 16, n. 28, p. 1-7, jan. 2017.

SOUZA, Alexandre Ramon de. Razão áurea e aplicações: contribuições para a aprendizagem de alunos de proporcionalidade de alunos do $9^{\circ}$ ano do Ensino Fundamental. 2013. 147f. Dissertação (Mestrado em Educação Matemática) — Instituto de Ciências Exatas e Biológicas. Universidade Federal de Ouro Preto. Ouro Preto.

STAKHOV, Alexey Petrovich. The Mathematics of Harmony: from Euclid to Contemporary Mathematics and Computer Science. Singapore: World Scientific, 2009.

TIESEN, Sandryne Maria de Campos; ARAUJO, Rafaele Rodrigues. O ensino de Matemática por meio da contextualização e da pesquisa. Educação Matemática Debate, Montes Claros, v. 4, n. 10, p. 1-16, 2020.

VOROBIOV, Nikolai Nikolayevich. Números de Fibonacci. Lecciones populares de matemáticas. Moscú: Editorial MIR, 1974. 